Matgorzata GóRsKa

\title{
Laciński genetivus possessivus (proprietatis) a modalność
}

Słowa klucze: genetivus possessivus, genetivus proprietatis, modalność, modalność deontyczna, modalność dynamiczna

Łaciński genetivus possessivus, czyli przypadek oznaczający najogólniej posiadanie, zwykle jest używany adnominalnie, tzn. jako tradycyjna przydawka rzeczowna dopełniaczowa, np. domus patris - dom ojca, ale może również pełnić funkcję predykatywną, tj. występować jako orzecznik, np. domus patris est-dom jest (własnościq) ojca. Gramatyki lacińskie wyodrębniają ponadto pewną specyficzną pododmianę genetiwu w funkcji predykatywnej, którą H. Menge (2000: 383) określa jako genetivus proprietatis, czyli genetivus właściwości. Genetivus ten, w połączeniu z formą słowa posiłkowego esse (być), tłumaczy się jako: 'jest cechą, właściwością, oznaką, przejawem, dowodem, zadaniem, obowiązkiem, powinnością' itp. ${ }^{1} \mathrm{~W}$ genetiwie zasadniczo występuje rzeczownik oznaczający osobę, o której cesze czy też obowiązku jest mowa, czyli taki, któremu przysługuje charakterystyka semantyczna +hum. Zamiast rzeczownika osobowego może być użyte pojęcie abstrakcyjne, którego coś jest oznaką czy przejawem. Jednakże ono

1 Por. np. Samolewicz, Sołtysik (2000: 54) czy Wikarjak (1978: 107). 
również, na zasadzie metonimii ${ }^{2}$, odnosi się do osoby. Podmiot gramatyczny, określający w tym przypadku działanie charakteryzujące jakąś osobę lub będące przejawem jakiejś cechy, ma zwykle postać bezokolicznika, niekiedy całego zdania (podmiotowego) rozpoczynającego się od spójnika $u t$. Zatem wypowiedzenia z genetiwem possessiwem $\mathrm{w}$ takim znaczeniu realizują schemat: $\mathrm{NP}_{\text {gen }}+\mathrm{V}_{\text {cop }}+$ inf $/$ sent $^{3}$.

To, jak w konkretnych wypowiedzeniach rozumieć esse z genetiwem, zależy oczywiście od kontekstu. I tak, np. Militis est fortiter pugnare może znaczyć Obowiąkiem żotnierza jest dzielnie walczyć lub Cecha żotnierza jest dzielnie walczyć, Stulti est in errore perseverare znaczy Cecha głupca jest trwanie w błędzie, a Stultitiae est in errore perseverare można rozumieć jako Oznaka / przejawem / dowodem głupoty jest trwanie w błędzie. Mimo że gramatyki jedynie wyliczają różne sposoby tłumaczenia omawianej konstrukcji ${ }^{4}$, dość wyraźnie rysują się jej dwa zasadnicze znaczenia, mianowicie 'jakieś działanie jest czyjąś cechą (lub oznaką czegoś)' oraz ‘jakieś działanie jest czyimś obowiązkiem'. Zwłaszcza to ostatnie rozumienie wskazuje, że konstrukcję tę można interpretować jako wykładnik modalności, czego, o ile mi wiadomo, jak dotąd nie dostrzeżono ${ }^{5}$. Spróbuję zatem wykazać, że geneti-

${ }^{2}$ Zob. Samolewicz, Sołtysik (2000: 274), Korolko (1990: 103) czy Głowiński [i in.] (2000, s.v. metonimia).

${ }^{3} \mathrm{NP}_{\text {gen }}$ oznacza rzeczownik w genetiwie, $\mathrm{V}_{\text {cop }}$ czasownik (esse) w funkcji łącznika, inf bezokolicznik, a sent zdanie. Oczywiście w tym przypadku jest to raczej wyliczenie elementów, które muszą się w takim wypowiedzeniu znaleźć, niż schemat wyodrębniony na podstawie kryteriów, przy użyciu których można wyodrębnić również inne schematy zdaniowe języka, w tym wypadku łacińskiego - próby takie można znaleźć w Happ (1976: 462-480) i Górska (1999). Schematy zdaniowe języka polskiego prezentują np. Szpakowicz, Świdziński (1998: 25-32), Saloni, Świdziński (1985: 264-265) oraz Grzegorczykowa (1996: 55-57).

${ }^{4}$ Zob. Menge (2000: 382-384), Kühner, Stegmann (1962: 452-454) czy Samolewicz, Sołtysik (2000: 54-55). W podobny sposób użycie esse z genetiwem przedstawiają także słowniki: Forcellini (1940: s.v. sum), Lewis, Short (1969: s.v. sum), Plezia (1999: s.v. sum).

${ }^{5} \mathrm{~W}$ nielicznych pracach omawiających łacińskie wykładniki modalności, które wyrażają zobowiązanie, wymienia się czasowniki debere (mieć obowiazek, musieć), oportet (należy, wypada, powinno się), wyrażenia nececesse est (jest konieczne), opus est (trze$b a$ ), konstrukcję z gerundivum (ozn. konieczność, przymus) - zob. Bolkestein (1980), Núñez (1991) czy Risselada (1993). G. Serbat (2002) opublikował artykuł pod obiecującym tytułem Un génitif de modalité?, jednak omawiany jest tam genetivus partitivus używany adwerbalnie (obok accusatiwu), który, zdaniem autora, ma pełnić funkcję modalną „,umniejszenia”. Nie wspomina on przy tym, jak rozumie modalność, ani też, jaki typ modalności tego rodzaju genetivus wyraża. 
vus possessivus (proprietatis) ma charakter modalny, co więcej, możliwa jest taka interpretacja, wg której obie jego odmiany służą do wyrażania dwóch podtypów tej samej modalności.

Modalność, określana najogólniej jako „Kategoria, której członami są predykaty wyrażające ustosunkowanie się mówiącego do treści dictum” (Polański 1993: s.v. modalność), jest różnie rozumiana, a co za tym idzie, różnie definiowana, różne też wymienia się jej typy ${ }^{6}$. W celu scharakteryzowania funkcji modalnych konstrukcji z genetiwem possessiwem (proprietatis) spośród wielkiej liczby ujęć, jaką można spotkać w literaturze przedmiotu, wybrałam typologię modalności zaproponowaną przez F. R. Palmera (2001: 7-10) $)^{7}$, ponieważ, jak już wspomniałam, pozwala ona zinterpretować modalnie oba użycia genetiwu possessiwu (proprietatis). Otóż Palmer wyróżnia dwie pary typów modalności: modalność e pistemiczną (epistemic modality) i ewidencjalną (evidential modality) oraz modalność deontyczną (deontic modality) i dynamiczną (dynamic modality). Modalności epistemiczna i ewidencjalna wyrażają stosunek nadawcy wobec prawdziwości albo stanu faktycznego propozycji, w związku z czym obie są podtypami modalności propozycjonalnej (propositional modality). Natomiast modalności deontyczna i dynamiczna określają stosunek nadawcy w odniesieniu do możliwego przyszłego wydarzenia, są więc podtypami modalności zdarzeniowej (event modality). Różnica między modalnością epistemiczną a ewidencjalną polega na tym, że przez modalność epistemiczną nadawca wyraża swoją ocenę stanu faktycznego propozycji, podczas gdy przez modalność ewidencjalną wskazuje na to, skąd pochodzi informacja na temat tego stanu faktycznego. Jeśli zaś chodzi o modalności deontyczną i dynamiczną, różnica między nimi sprowadza się do tego, że ta pierwsza

${ }^{6}$ Różne definicje i typy modalności prezentują np. Kiefer (1987), Narrog (2005), Le Querler (1996), Bybee, Perkins, Pagliuca (1994: 176-242) czy Bybee, Fleischman (1995). Portner (2009) omawia różne ujęcia metodologiczne modalności, m.in. te, które proponują lingwistyki funkcjonalna i kognitywna.

7 Opieram się tu na drugim wydaniu pracy Palmera, zatytułowanej Mood and Modality, które znacznie różni się od wydania pierwszego (Palmer 1986), także w kwestii wyodrębniania typów modalności.

8 Autor zwraca przy tym uwagę, że różnicę między modalnością zdarzeniową a modalnością propozycjonalną można scharakteryzować, odwołując się do rozróżnienia wprowadzonego przez Jespersena (1924: 329-331), mianowicie tę pierwszą można określić jako „containing an element of will”, a drugą jako „,containing no element of will”. 
jest warunkowana czynnikami zewnętrznymi w stosunku do odbiorcy, natomiast ta druga wewnętrznymi. W związku z tym modalność deontyczna określa zobowiązanie (obligation) albo pozwolenie (permission), które wypływają ze źródła zewnętrznego, natomiast modalność dynamiczna wyraża zdolność (ability) lub wolę (willingnes) właściwą odbiorcy. Autor ilustruje te różnice następującymi przykładami:

John may/can come in now

John must come in now

John can speak French

John will do it for you (permission)

(obligation)

(ability)

(willingness)

Dookreślając zdolność (ability), stwierdza ponadto, że należy ją rozumieć nie tylko jako subiektywne fizyczne i mentalne zdolności, ale także szerzej, jako bardziej ogólną, wynikającą z okoliczności, możliwość zrobienia czegoś, co pokazuje w zdaniach:

John can run a mile in five minutes

(he has the ability)

John can escape

(the door's not locked)

Jeśli zaś chodzi o modalność deontyczną, przypomina, że jej źródłem jest jakiś rodzaj zewnętrznego autorytetu, np. zasady prawa, a w typowej sytuacji autorytetem tym jest nadawca' 9

W związku z tym, że artykuł ten dotyczy konstrukcji z genetiwem possessiwem (proprietatis), interesować nas będzie wyróżniona przez Palmera modalność zdarzeniowa (event modality). Jak się bowiem wydaje, dwa wskazane wcześniej sposoby użycia tej konstrukcji można interpretować jako wykładniki dwóch jej podtypów: modalności dynamicznej i deontycznej. Kiedy bowiem 'jakieś działanie jest czyjąś cechą, znaczy to, że ten ktoś ma jakąś zdolność (ability - modalność dynamiczna), a gdy ‘jakieś działanie jest czy-

${ }^{9}$ Lyons (1989: 428) ujmuje to w następujący sposób: „[...] konieczność i możliwość deontyczną rozumiemy zazwyczaj jako wypływającą z określonego źródła przyczynowego. Innymi słowy, przyjmuje się zazwyczaj, że jeśli ktoś jest obowiązany lub upoważniony do jakiegoś postępowania, to ten obowiązek lub upoważnienie ustanowiła jakaś osoba lub instytucja [...]. Nazwijmy tę osobę lub instytucję źródłem deontycznym”. Zob. też Jędrzejko (1987: 25-26). 
imś obowiązkiem', wynika stąd, że jest na niego nałożony jakiś obowiązek (obligation - modalność deontyczna). Inaczej mówiąc, jeśli robienie czegoś jest czyjąś cechą (właściwością), znaczy to, że ten ktoś może to robić (jest do tego zdolny), a jeśli robienie czegoś jest czyimś obowiązkiem, znaczy to, że ten ktoś musi to robić (jest do tego zobowiązany) ${ }^{10}$. Do zilustrowania tych dwóch funkcji genetiwu possessiwu posłużę się przykładami zaczerpniętymi z dzieł Cycerona ${ }^{11}$. I tak, w następujących fragmentach tekstów pojawiają się konstrukcje $\mathrm{z}$ genetiwem possessiwem (proprietatis), wyrażające modalność dynamiczną - czyjąś zdolność do czegoś, co mniej lub bardziej wyraźnie oddają ich literackie przekłady:

(1) ...mirique sunt orbes et quasi circumitus in rebus publicis commutationum et vicissitudinum; quos cum cognosse sapientis est, tum vero prospicere inpendentis in gubernanda re publica moderantem cursum atque in sua potestate retinentem magni cuiusdam civis et divini paene est viri. (Cic. Rep. 1, 45)

Dziwne są te koła czy kręgi kolejno zachodzących w państwach zmian i przeobrażeń! Pojąć je może tylko mędrzec. Przewidzieć zaś ich zbliżanie się, by rządząc państwem pokierować ich przebiegiem i zachować nad nimi swą moc, potrafi tylko jakiś wielki obywatel, nieledwie równy bogom.

(2) At non est integrum: constituta legatio est. Quid autem non integrum est sapienti quod restitui potest? Cuiusvis hominis est errare; nullius nisi insipientis perseverare in errore. (Cic. Phil. 12, 5)

Ponoć mamy spętane ręce, bo uchwalono wysłanie poselstwa. Czy mądrego człowieka krępuje, gdy musi zmieniać decyzję? Myli się każdy, tylko głupiec trwa w błędzie.

(3) ...cumque ea maxime animum moveat tum tibi esse diligentissime linguam continendam; quae quidem mihi virtus interdum non minor vide-

10 Por. inne niż podane wcześniej propozycje tłumaczenia konstrukcji z genetiwem possessiwem (proprietatis) w Samolewicz, Sołtysik (2000: 54): „W języku polskim używa się często jeszcze innych wyrażeń, np. „wymagać, dowodzić, musieć, móc, pozwolić, zgadzać się, przystoi, wypada" itp."

11 Przy przytaczaniu fragmentów twórczości Cycerona zastosowany został system skrótów przyjęty w Plezia (1999: XLIII-XLIV). Lista zamieszczonych tu przekładów literackich znajduje się na końcu artykułu. 
tur quam omnino non irasci. nam illud est non solum gravitatis sed non numquam etiam lentitudinis; moderari vero et animo et orationi cum sis iratus, aut etiam tacere et tenere in sua potestate motum animi et dolorem, etsi non est perfectae sapientiae, tamen est non mediocris ingenii (Cic. Q. fr 1, 1, 38)

...a gdy się najbardziej rozgniewasz, wtenczas najpilniej język na wodzy trzymać masz, co zdaje mi się czasem nie mniejszą cnotą, jak się zgoła nie rozgniewasz. Bo przyczyną tego ostatniego jest nie tylko panowanie nad sobą, ale czasem brak drażliwości; ale wśród gniewu umieć się pohamować i powstrzymać język, nad gwałtowniejszym wzruszeniem umysłu panować i milczeć, jeśli nie jest znakiem madrości, to przynajmniej niepospolitej mocy rozuтu.

W przykładzie (1) tłumaczenie dobrze pokazuje, że jest tu mowa o zdolności, w tym przypadku pojmowania i przewidywania, w (2) łatwo zmodyfikować przekład, by było to wyraźniejsze: „Każdy może się mylić, tylko głupiec może trwać w błędzie". W przykładzie (3) natomiast mamy do czynienia z sytuacją wspomnianą na początku, polegającą na tym, że w genetiwie pojawia się nie rzeczownik osobowy, określający kogoś, kto przejawia jakąś zdolność, a rzeczownik abstrakcyjny, czy też ściślej rzeczowniki abstrakcyjne: sapientia (madrość) i ingenium (rozum). Jest to jednak, jak się wydaje, metonimia, polegającą w tym wypadku na zastąpieniu nazwy osoby nazwą jakiejś jej cechy i w gruncie rzeczy sens zdania jest taki: ,zdolny do powstrzymania się od mówienia jest, jeśli nie mądry, to przynajmniej rozumny".

Jako przykłady użycia genetiwu possessiwu (proprietatis) dla wyrażenia zobowiązania mogą posłużyć następujące fragmenty z Cycerona:

(4) Et quoniam officia non eadem disparibus aetatibus tribuuntur aliaque sunt iuvenum, alia seniorum, aliquid etiam de hac distinctione dicendum est. Est igitur adulescentis maiores natu vereri exque iis deligere optimos et probatissimos, quorum consilio atque auctoritate nitatur... (Cic. Off. 1, 34)

A że nie takie same powinności przypadają w udziale różnym okresom życia i inne są obowiązki młodzieńców, inne zaś ludzi starszych, wypada coś powiedzieć i o tej różnicy. Powinnością tedy młodzieńca jest szanować ludzi starszych wiekiem i wybierać spomiędzy nich najlepszych i najdoświadczeńszych, by móc oprzeć się na ich radzie i powadze... 
(5) Et iudicare difficile est sane nisi expertum; experiendum autem est in ipsa amicitia. Ita praecurrit amicitia iudicium tollitque experiendi potestatem. Est igitur prudentis sustinere ut cursum, sic impetum benivolentiae, quo utamur quasi equis temptatis, sic amicitia ex aliqua parte periclitatis moribus amicorum. (Cic. Lael. 63,1)

W dodatku nader trudno jest ocenić człowieka bez wypróbowania go, a wypróbować można dopiero w samej przyjaźni. Tak oto przyjaźń wyprzedza ocenę i odbiera możność wypróbowania. Powinnościa tedy człowieka roztropnego jest powstrzymywanie zapędów własnej życzliwości niby nazbyt szybkiego biegu i korzystanie z przyjaźni w taki sposób, w jaki korzysta się z ujeżdżonych koni - po uprzednim poznaniu, w pewnej mierze przynajmniej, charakterów przyjaciół.

(6) Populi grati est praemiis adficere bene meritos de re publica civis, viri fortis ne suppliciis quidem moveri ut fortiter fecisse paeniteat. (Cic. Mil. 82, 10)

Należy to do wdzięcznego narodu, nagradzać dobrze zasłużonych ojczyźnie obywatelów: należy do prawdziwego obywatela na placu nawet stracenia nie żałować mężnego czynu.

Polskie tłumaczenia, w których zostały użyte wyrażenia ,jest powinnością”, „należy”, wskazują, że występujące w przykładach (4)-(6) konstrukcje $\mathrm{z}$ genetiwem proprietatis są interpretowane deontycznie, a nie dynamicznie. Może się w związku z tym pojawić pytanie, na jakiej podstawie dokonuje się rozgraniczenie tych dwóch użyć. Jak się wydaje, podobnie jak w przypadku innych polifunkcyjnych wykładników modalności, decyduje o tym kontekst ${ }^{12}$. Przykłady (1)-(3) wyraźnie wykluczają interpretację deontyczną: w (1) obywatel niemal równy bogom ma zdolność (a nie obowiązek) przewidywania zmian, w (2) mylenie się jest cechą (a nie obowiązkiem) każdego,

12 Dotyczy to chociażby czasowników modalnych móc i musieć: w zależności od kontekstu zdanie Jan może przyjść będzie wyrażało przypuszczenie („Jest możliwe, że Jan przyjdzie" - modalność epistemiczna) albo pozwolenie („Janowi wolno przyjść" modalność deontyczna), a zdanie Jan musi być w pracy może wyrażać nakaz (,Jan ma obowiązek być w pracy" - modalność deontyczna) albo przypuszczenie oparte na wnioskowaniu („Jan prawdopodobnie jest teraz w pracy, bo zawsze o tej porze tam jest” - modalność ewidencjalna). 
podobnie trwanie w błędzie jest cechą (a nie powinnością) głupca, a w (3) umiejętność powstrzymywania gniewu jest cechą (a nie obowiązkiem) wybitnego umysłu. Natomiast w przykładach (4)-(6) kontekst wskazuje, że konstrukcja z genetiwem proprietatis wyraża nie tyle taką cechę czy zdolność, którą ktoś się charakteryzuje, ile taką, której się od niego oczekuje, wymaga: w (4) jest powiedziane wprost, że wymienione będą obowiązki, w tym przypadku ludzi młodych, w (5) sens jest taki, że ponieważ niełatwo ocenić człowieka, roztropność wymaga pewnej powściągliwości (a nie charakteryzuje się nią), a w (6) jest mowa o tym, że dzielny obywatel powinien być gotowy na największe nawet poświęcenie, a wdzięczny naród powinien nagradzać zasługi (a nie jest do tego zdolny).

Zakładając, że kontekst pozwala odróżnić konstrukcje z genetiwem proprietatis określające zdolność od tych określających powinność, omówienia wymaga to, jaki jest charakter tej powinności, tzn. czy mamy w tym wypadku rzeczywiście do czynienia z koniecznością deontyczną, a nie epistemiczną. Problem rozróżniania tych dwóch rodzajów konieczności jest dość skomplikowany i stanowi przedmiot rozważań wielu badaczy, między innymi J. Lyonsa (1989: 409-434). Ponieważ jego szczegółowe zaprezentowanie nie jest tu możliwe, upraszczając, można stwierdzić, że sprowadza się on do tego, czy zdania tego typu konstytuują akty mowy określane jako dyrektywy, które Palmer definiuje za J. R. Searle'em (1983: 166) tak: „Where we try to get [others] to do things" (Palmer 2001: 10). Odpowiedzi na te pytania mogą być różne. Warunki, jakie muszą spełniać zdania $\mathrm{z}$ łacińskim czasownikiem debere (mieć obowiązek, musieć), wyrażeniem nececesse est (jest konieczne) i konstrukcją z gerundivum (ozn. konieczność, przymus), by uznać je za dyrektywy, a tym samym wykładniki modalności deontycznej, omawia M. Bolkestein (1980: 52-80). Można je streścić następująco: zdania te muszą występować w czasie teraźniejszym, muszą odnosić się do jakiegoś specyficznego (tj. nieogólnego) stanu rzeczy, który jest w jakiś sposób kontrolowany przez odbiorcę, musi być wskazane deontyczne źródło zobowiązania ${ }^{13}$. Na podstawie przykładów (4)-(6) wypada stwierdzić, że zdania z genetiwem proprietatis tych warunków nie spełniają. Jest w nich wprawdzie używany praesens, ale oznaczający wszechczasowość, zatem nadaje im sens stwier-

13 Jeśli jakieś zdanie nie spełnia choćby jednego z tych warunków, jest traktowane jako wyrażające konieczność epistemiczną, w terminologii Bolkestein jest to zdanie nie deontyczne, a inferencjalne. 
dzeń ogólnych ${ }^{14}$. Ogólny charakter tych zdań przejawia się ponadto w tym, że rzeczownik w genetiwie jest zwykle używany niereferencjalnie. W sytuacji bowiem, gdy zdanie ma się odnosić wprost do określonej osoby, zamiast genetiwu zaimka osobowego stosowany jest zaimek dzierżawczy w nominatiwie w rodzaju nijakim ${ }^{15}$ :

(7) His tantis in rebus tantisque in periculis est tuum, M. Cato, qui mihi non tibi, sed patriae natus esse videris, videre, quid agatur, retinere adiutorem, defensorem, socium in re publica, consulem non cupidum, consulem, quod maxime tempus hoc postulat... (Cic. Mur. 83, 1)

W tej sytuacji, wobec takiego niebezpieczeństwa, Katonie - ponieważ moim zdaniem urodziłeś się nie dla siebie, ale dla dobra rzeczypospolitej powinienieś czuwać nad tym, co się dzieje, zatrzymać w rzeczypospolitej pomocnika, obrońcę, współpracownika, konsula niezachłannego, konsula, jakiego pilnie domagają się nasze czasy...

Wyjątek stanowią zdania, gdzie w genetiwie, zamiast nazwy osoby, pojawia się nazwa jej cechy z przydawką w postaci zaimka dzierżawczego ${ }^{16}$ :

(8) Quapropter incumbe toto animo et studio omni in eam rationem qua adhuc usus es, ut eos quos tuae fidei potestatique senatus populusque Romanus commisit et credidit diligas et omni ratione tueare et esse quam beatissimos velis. quod si te sors Afris aut Hispanis aut Gallis praefecisset, immanibus ac barbaris nationibus, tamen esset humanitatis tuae consulere eorum commodis et utilitati salutique servire... (Cic. Q. fr. 1, 1, 27)

Przykładaj się tedy z całą usilnością i gorliwością, jak dotąd czyniłeś, do tego, żebyś ludzi, których senat i lud Rzymski poruczył i powierzył twojej

14 Zob. np. Samolewicz, Sołtysik (2000: 108).

15 Por. Samolewicz, Sołtysik (2000: 55), Menge (2000: 384), Kühner, Stegmann (1962: 454). W najnowszym opracowaniu dotyczącym modalności w łacinie E. Magni (2010: 210), wymieniając łacińskie formy semimodalne, tzn. takie, które mogą wyrażać modalność dynamiczną i deontyczną, a nie mogą być używane jako wykładniki modalności epistemicznej, wspomina to wyrażenie: „....semimodal forms are ... expressions indicating various shades of necessity such as meum, tuum, ius, aequum, par... est 'it is my, your duty; it is just, right, proper'..."

$16 \mathrm{~W}$ podanym przykładzie słowo posiłkowe występuje w coniunktiwie imperfecti, ponieważ jest częścią okresu warunkowego. 
władzy i pieczołowitości, kochał, wszelkiemi siłami bronił, i jak najwięcej uszczęśliwił. Gdyby cię los nad Afrykanami, Hiszpanami lub Gallami przełożył, dzikiemi i barbarzyńskiemi narodami, nie mniej atoli byłoby powinnościa twojej ludzkości ich dobro i pożytek obmyślać, i nad ich zachowaniem pracować...

Chociaż zdania takie jak w przykładach (4)-(6) nie wyrażają według kryteriów ustalonych przez Bolkestein modalności deontycznej, użyte w określonym kontekście są jednak, jak się wydaje, dyrektywami, tzn. za ich pomocą nadawca, który sam jest źródłem deontycznym lub tylko zgadza się z pełniącą tę rolę kulturowo uwarunkowaną ogólną opinią, stawia odbiorcę w stan zobowiązania. Zatem bardziej uzasadnione będzie przyjęcie takiego rozumienia dyrektyw, jakie można znaleźć np. u R. Grzegorczykowej (2002: 134), która tego typu zdania, realizujące według niej modalność deontyczną, określa jako „wypowiedzi postulatywne w obrębie intencjonalnych deklaratywów, a więc wypowiedzi informujące o postawie wolitywno-oceniającej nadawcy [...]” i stwierdza, że „Wartość dyrektywna tych zdań, a więc chęć wpłynięcia na słuchacza, nie jest sygnalizowana wprost, jest ukryta, pozostawiona niejako wnioskowaniu i dobrej woli odbiorcy [...]" (Grzegorczykowa 2002: 128).

Mimo zasygnalizowanych wyżej możliwych trudności ze ścisłym rozgraniczeniem różnych użyć konstrukcji z genetiwem possessiwem (proprietatis) czy ewentualnych problemów z ustaleniem, jakiego typu akt mowy konstytuuje, propozycja uznania jej za wykładnik dwóch podtypów modalności zdarzeniowej zasługuje, jak się wydaje, na rozważenie, ponieważ pozwala na spójne ujęcie tego zjawiska gramatycznego.

\section{Źródła:}

Cic. Fam.: Cyceron M. T., 1873, Listy, t. 2, tłum. E. Rykaczewski, Poznań: Biblioteka Kórnicka.

Cic. Lael.: Cicero M. T., 1963, O przyjaźni, w: tenże, Pisma filozoficzne, t. 4, tłum. W. Kornatowski, Warszawa: PWN.

Cic. Mil.: Cyceron M. T., 1871, Mowy, t. 3, tłum. E. Rykaczewski, Paryż: Biblioteka Kórnicka. 
Cic. Mur.: Cyceron M. T., 1998, Mowa w obronie Mureny, tłum. J. Mrukówna, w: tenże, Mowy, Kęty: Wydawnictwo Antyk.

Cic. Off:: Cicero M. T., 1960, O powinnościach, w: tenże, Pisma filozoficzne, t. 2, tłum. W. Kornatowski, Warszawa: PWN.

Cic. Phil.: Cyceron M. T., 2002, Filipiki. Mowy przeciwko Markowi Antoniuszowi, tłum., wstępem i przypisami opatrzyła K. Ekes, Warszawa: Prószyński i S-ka.

Cic. Q. fr.: Cyceron M. T., 1873, Listy, t. 1, tłum. E. Rykaczewski, Poznań: Biblioteka Kórnicka.

Cic. Rep.: Cicero M. T., 1960, O państwie, w: tenże, Pisma filozoficzne, t. 2, tłum. W. Kornatowski, Warszawa: PWN.

\section{Bibliografia}

Bolkestein A. M., 1980, Problems in the description of modal verbs. An investigation of Latin, Assen: Van Gorcum.

Bybee J., Fleischman S. (red.), 1995, Modality in Grammar and Discourse, Amsterdam-Philadelphia: John Benjamins Publishing Company.

Bybee J., Perkins R., Pagliuca W., 1994, The Evolution of Grammar. Tense, Aspect and Modality in the Languages of the World, Chicago-London: The University of Chicago Press.

Forcellini E., 1940, Lexicon totius Latinitatis, t. 4, Patavii: Typis Seminarii.

GŁowiński M., Kostkiewiczowa T., Okopień-SŁawińska A., SŁawiński J., 2000, Słownik terminów literackich, Wrocław: Zakład Narodowy im. Ossolińskich.

Górska M., 1999, Gramatyka zależności a nauczanie składni łacińskiej, Roczniki Humanistyczne 47, z. 3, s. 105-122.

GrzegorczyKowa R., 1996, Wykłady z polskiej składni, Warszawa: Wydawnictwo Naukowe PWN.

GrZegorczyKowa R., 2002, Wprowadzenie do semantyki językoznawczej, Warszawa: Wydawnictwo Naukowe PWN.

Happ H., 1976, Grundfragen einer Dependenzgrammatik des Lateinischen, Göttingen: Vandenhoeck und Ruprecht.

Jespersen O., 1924, The Philosophy of Grammar, London: Allen and Unwin.

JęDRZEJKo E., 1987, Składnia i semantyka polskich czasowników deontycznych, Wrocław: Zakład Narodowy im. Ossolińskich.

Kiefer F., 1987, On defining modality, Folia Linguistica 21(1), s. 67-94.

Korolko M., 1990, Sztuka retoryki. Przewodnik encyklopedyczny, Warszawa: Wiedza Powszechna. 
Kühner R., Stegmann C., 1962, Ausführliche Grammatik der lateinischen Sprache. Satzlehre I, München: Max Hueber Verlag.

Le Querler N., 1996, Typologie des modalités, Caen: Presses Universitaires de Caen.

Lewis Ch. T., Short CH. (red.), 1969, Latin Dictionary, Oxford: Clarendon Press.

Lyons J., 1989, Semantyka 2, tłum. A. Weinsberg, Warszawa: Wydawnictwo Naukowe PWN.

Magni E., 2010, Mood and Modality, w: F. Baldi, P. Cuzzolin (red.), New Perspectives on Historical Latin Syntax, Vol. 2: Constituent Syntax: Adverbial Phrases, Adverbs, Mood, Tense, Berlin-New York: De Gruyter Mouton, s. 193-276.

Menge H., 2000, Lehrbuch der lateinischen Syntax und Semantik, Völlig neu bearbeitet von T. Burkard und M. Schauer, Darmstadt: Wissenschaftliche Buchgesel1schaft.

Narrog H., 2005, On defining modality again, Language Sciences 27/2, s. 165-192.

NúÑEz S., 1991, Semántica de la modalidad en latín, Granada: Universidad de Granada.

Palmer F. R., 1986, Mood and Modality, Cambridge: Cambridge University Press.

Palmer F. R., 2001, Mood and Modality, Cambridge: Cambridge University Press.

Plezia M. (red.), 1999, Słownik łacińsko-polski, t. 1-5, Warszawa: Wydawnictwo Naukowe PWN.

Polański K. (red.), 1993, Encyklopedia językoznawstwa ogólnego, Wrocław: Zakład Narodowy im. Ossolińskich.

Portner P., 2009, Modality, Oxford: Oxford University Press.

RisseladA R., 1993, Imperatives and other directive expressions in Latin: a study in the pragmatics of a dead language, Amsterdam: J. C. Gieben Publisher.

SAloni Z., ŚwidziŃSKi M., 1985, Składnia współczesnego języka polskiego, Warszawa: Wydawnictwo Naukowe PWN.

Samolewicz Z., SoŁtysik T., 2000, Składnia łacińska, wydanie poprawione pierwsze, oprac. K. Bielawski i A. Gorzkowski, Bydgoszcz: Wydawnictwo Homini.

Searle J. R., 1983, Intentionality, Cambridge: Cambridge University Press.

Serbat G., 2002, Un génitif de modalité?, w: M. Fruyt, C. Moussy (red.), Les modalités en latin. Actes du Colloque de Centre Ernout: 3, 4, 5 juin 1998; Paris IV, Paris: Presses de l'Univ. de Paris-Sorbonne, s. 265-273.

SzPakowicz S., ŚwidziŃski M., 1982, Zarys klasyfikacji schematów zdaniowych we współczesnej polszczyźnie pisanej, Polonica 7, s. 5-35.

WiKARJAK J., 1978 [2006, wyd. 11], Gramatyka opisowa języka łacińskiego, Warszawa: Wydawnictwo Naukowe PWN. 


\section{Latin genetivus possessivus (proprietatis) versus modality}

( su m mary)

The paper seeks to interpret the est + genetivus possessivus (proprietatis) construction as a marker of the two subtypes of event modality, i.e. deontic and dynamic modality. This distinction is made on the basis of the typology proposed by F. R. Palmer (2001). The difference between deontic and dynamic modality 'is that with deontic modality the conditioning factors are external to the relevant individual, whereas with dynamic modality they are internal' (Palmer 2001: 9-10). Genetivus possessivus as a marker of deontic modality represents obligation 'emanating from an external source', whereas as a marker of dynamic modality it expresses ability 'which comes from the individual concerned.' 
